\title{
Reduced Fare Programs for Older Adults and Persons with Disabilities: A Peer Review of Policies
}

\author{
Gregory L. Newmark \\ Center for Neighborhood Technology, Chicago
}

\begin{abstract}
A significant but understudied activity of transit agencies is managing reduced fare programs for older adults and people with disabilities. The laws that mandate these programs afford transit agencies substantial latitude in designing implementations. Although the resultant program variation offers an excellent opportunity for agencies to learn from each other's experiences, there has been little comparative analysis. This paper addresses this knowledge gap by providing, for the first time, a systematic consideration of reduced fare policies at the major transit agencies in the 10 most populous metropolitan regions in the United States. This work combines the findings of a structured, open-ended survey with information gleaned from transit agency websites to identify the core components of a reduced fare program, illustrate extant program variation, and discuss the attendant tradeoffs. The goal of this paper is to assist agencies seeking to re-examine and refine their reduced fare program practices.
\end{abstract}

\section{Introduction}

A nearly universal feature of transit in developed economies is the provision of reduced fares for older adults and people with disabilities. Such concessionary fares help public transportation meet its public objective of expanding mobility for disadvantaged populations. The number of people currently enrolled in concession- 
ary fare programs is substantial. Chicago, for example - the third largest metropolitan area in the United States-has more than a half million registered reduced fare riders. These numbers are going to grow as demographic shifts continue to increase both the absolute numbers and the relative shares of eligible populations.

While it is always recommended practice for transit agencies to review their policies, the current transition to contactless fare media and open fare payment systems has focused attention on reduced fare programs. Successful reviews entail examining alternative models implemented by peer agencies. Unfortunately, there are no extant comparisons of concessionary fare policies to guide agencies seeking to revise and refine their own reduced fare programs. Alternative models do exist, as the laws that require concessionary fares be offered generally do not specify how those fare reductions are to be offered; however, the absence of a systematic comparison increases the likelihood that the innovations and unique adaptations developed in one place are not known elsewhere.

This paper seeks to fill this knowledge gap. This research surveys reduced fare policies among a pre-existing peer group of 10 major transit properties in the United States. Through analysis of the data collected, the core activities that characterize a reduced fare program are clustered into three areas: fundamentals, administration, and fraud prevention. This tripartite taxonomy is then used to structure the comparison of concessionary fare practices. This effort is designed to illustrate the range of practices and their attendant trade-offs without elevating any individual approach as a "best" practice. The goal of this work is to provide a framing grammar and illustrative vocabulary of reduced fare policy to enable interested transit agencies to discuss and define the practices that fit them best.

\section{Background}

United States law since 1976 requires, in somewhat dated language, that all transit agencies receiving federal funds give satisfactory assurances that "the rates charged to elderly and handicapped persons during non-peak hours ... will not exceed onehalf of the rates generally applicable to other persons at peak hours" (U.S. Department of Transportation 1976). 
The regulations do not mandate any specific program administration. To date, studies of concessionary fares have only obliquely addressed the resultant policy variation. For example, Metz (2003) notes that in England, "there has been wide variation in the terms of the [older adult reduced fare] schemes that have been offered," but does not examine that variation. Instead, studies on reduced fare programs for older adults and persons with disabilities focus on ridership and revenue (Roszner and Hoel 1971; Ling and Howcroft 2007; Morlok, Kulash, and Vandersypen 1971; Hoel and Roszner 1972; Rye and Mykura 2009; Baker and White 2010; Truelove 1984; Andrews et al. 2012; Schmöcker et al. 2008; Shmelzer and Cantilli 1970; Rye et al. 2002) or equity impacts (Rock 1979; Andrews et al. 2012; Shmelzer and Cantilli 1970). The one exception (Ketron, Inc., and Urban Mass Transportation Authority 1981) catalogs the variation in reduced fare schemes then operating in the greater New York City region; however, the purpose of that cataloging was as a basis for a proposal to align the policies rather than explore their distinctions.

The current research takes a different tack and focuses on the reduced fare policies themselves with an appreciation of their diversity and a consideration of the associated trade-offs.

\section{Methodology}

This qualitative research combines a structured, open-ended survey of managers of reduced fare programs for older adults and persons with disabilities with materials available on the agency websites. The study sample consists of the largest transit agencies in the 10 most populous U.S. metropolitan areas. Table 1 lists these regions, which comprise an existing peer comparison group (Gallucci and Allen 2011) and the surveyed transit agency. For ease of expression, the region name is used in place of the transit agency throughout this text.

The survey results were analyzed to identify core elements common to all reduced fare programs. These elements were organized into a tripartite structure of fundamentals, administration, and fraud prevention. This structure provides a frame for considering all the activities associated with a concessionary fare policy. Fundamentals define the underlying program benefits as well as the technology for proving authorization for those benefits. Administration defines the three key processes of registration, renewal, and card replacement necessary for customers to obtain and maintain authorization for participation in the program. Fraud prevention includes all techniques and practices to prevent abuse and limit the benefit of the program to authorized users. 
Table 1. Regional Information and Transit Agencies Surveyed

\begin{tabular}{|l|r|r|r|l|}
\hline \multicolumn{1}{|c|}{ Region* } & Population & \multicolumn{1}{|c|}{ Area } & \multicolumn{1}{c|}{ Boardings } & \multicolumn{1}{|c|}{ Agency Surveyed** } \\
\hline Atlanta & $5,359,205$ & 8,339 & $144,324,818$ & $\begin{array}{l}\text { Metropolitan Atlanta Rapid Transit } \\
\text { Authority (MARTA) }\end{array}$ \\
\hline Boston & $4,591,112$ & 3,487 & $380,694,311$ & $\begin{array}{l}\text { Massachusetts Bay Transportation } \\
\text { Authority (MBTA) }\end{array}$ \\
\hline Chicago & $9,504,753$ & 7,197 & $641,388,305$ & Regional Transportation Authority (RTA) \\
\hline Dallas & $6,526,548$ & 8,928 & $70,820,990$ & Dallas Area Rapid Transit (DART) \\
\hline Houston & $6,086,538$ & 8,827 & $81,085,192$ & $\begin{array}{l}\text { Metropolitan Transit Authority of Harris } \\
\text { County (Metro) }\end{array}$ \\
\hline Los Angeles & $12,944,801$ & 4,848 & $660,858,338$ & $\begin{array}{l}\text { Los Angeles County Metropolitan } \\
\text { Transportation Authority (LACMTA) }\end{array}$ \\
\hline Miami & $5,670,125$ & 5,077 & $157,722,546$ & Miami-Dade Transit (MDT) \\
\hline $\begin{array}{l}\text { New York } \\
\text { City }\end{array}$ & $19,015,900$ & 6,687 & $3,787,042,294$ & New York City Transit (NYCT) \\
\hline Philadelphia & $5,992,414$ & 4,602 & $369,349,558$ & $\begin{array}{l}\text { Southeastern Pennsylvania } \\
\text { Transportation Authority (SEPTA) }\end{array}$ \\
\hline Washington & $5,703,948$ & 5,598 & $455,528,801$ & $\begin{array}{l}\text { Washington Metropolitan Area Transit } \\
\text { Authority (WMATA) }\end{array}$ \\
\hline
\end{tabular}

*Region: Populations are for associated metropolitan statistical area (MSA) in 2011. Areas are in square miles for associated MSA. Boardings are for selected transit agencies within an MSA based on their reporting for 2011 to the National Transit Database. The selection procedure is described by Allen (2013) and includes most operators reporting at least 4 million annual boardings. The one exception is the exclusion of NJ Transit, whose contribution to both New York and Philadelphia cannot be appropriately broken out. The enumerated list of included providers can be found in the "2011 Regional Peer Report Card" (RTA Department of Finance and Performance Management 2013).

${ }^{* *}$ Agency Surveyed: Represents largest transit agency of MSA. In places such as Chicago, Los Angeles, and New York, selected agency runs reduced fare program for multiple operators.

\section{Fundamentals}

Reduced fare programs offer the benefit of a cost reduction to authorized users. Those users demonstrate their authorization by presenting a permit issued by the transit agency. This section introduces those benefits and the accompanying permit technologies. 


\section{Benefits}

United States law requires that transit properties offer half-price fares only during off-peak hours. The surveyed agencies all exceed this minimum temporal requirement and offer reduced fares throughout the day. Extending the hours of reduced rates is politically popular and facilitates handling of the discounts, particularly as relatively few systems maintain peak/off-peak distinctions in their pricing structures; however, such policies are theoretically problematic from a system performance perspective since they likely marginally increase transit demand during peak periods when transit supply is most limited (and most costly to provide).

Two systems do tweak their policies to better match demand and supply. Los Angeles offers deeper fare reductions during the off-peak period to encourage ridership when more capacity is available. Conversely, New York does not offer fare reductions on express buses during the morning rush when capacity is most desired. No respondent mentioned any system interest in scaling back the benefits to only off-peak periods.

The surveyed agencies also all exceed the minimum reduction requirement and offer free transit to at least one population group, as shown in Table 2.

Free transit is most commonly offered to people eligible for ADA paratransit service as a cost-saving measure designed to shift their trips to the far less subsidized fixed-route service. For example, New York, which started its free trip program in 2013, anticipates saving up to $\$ 90$ million per year in subsidies (Newman 2012), and Washington claims $\$ 25$ million in savings for fiscal year 2011 (Metro Staff 2012). Such programs are not without reported problems including large increases in ADA paratransit applicants (and consequently in labor costs for completing the additional eligibility determinations), illegal use of ADA paratransit permits by ineligible people, and counterfeiting of such permits. To limit these abuses, Washington restricts the free transit benefit to conditionally eligible riders (i.e., certified as physically able to use the fixed-route system for some trips) (Metro Staff 2012); Boston restricts the benefit to riders who have been in the ADA paratransit program for at least a year; and, New York restricts free travel to a maximum of four fixed-route trips per day (Goldstein 2013). 
Table 2. Reduced Fare Policy Comparison

\begin{tabular}{|c|c|c|c|c|c|c|c|c|c|c|}
\hline Policy & Atlanta & Boston & Chicago & Dallas & Houston & Los Angeles & Miami & New York & Philadelphia & Wash DC \\
\hline \multicolumn{11}{|l|}{ Fundamentals } \\
\hline \multicolumn{11}{|l|}{ Free fixed-route transit for: } \\
\hline All ADA paratransit eligible & $\bullet$ & $\bullet$ & $\circ$ & $\bullet$ & $\circ$ & $\bullet$ & $\bullet$ & $\bullet$ & $\circ$ & ○ \\
\hline Conditionally eligible for ADA paratransit & o & o & o & o & o & o & $\circ$ & o & o & - \\
\hline All older adults (in Houston those over age 70) & $\circ$ & $\circ$ & $\circ$ & $\circ$ & $\bullet$ & $\circ$ & $\bullet$ & $\circ$ & $\bullet$ & $\circ$ \\
\hline $\begin{array}{l}\text { Older adults/persons with disabilities who pass } \\
\text { a means test }\end{array}$ & 0 & $\circ$ & - & 0 & $\circ$ & 0 & $\circ$ & $\circ$ & 0 & $\circ$ \\
\hline \multicolumn{11}{|l|}{ Card technologies in use: } \\
\hline Identification-only card & $\circ$ & $\circ$ & $\circ$ & $\bullet$ & $\circ$ & $\circ$ & $\circ$ & $\circ$ & $\bullet$ & $\bullet$ \\
\hline Combined identity and fare card: smartcard & $\bullet$ & $\bullet$ & $\circ$ & $\circ$ & $\bullet$ & $\bullet$ & $\bullet$ & ० & $\circ$ & $\circ$ \\
\hline Combined identity and fare card: magnetic stripe & $\circ$ & $\circ$ & $\bullet$ & $\circ$ & $\circ$ & $\circ$ & $\circ$ & $\bullet$ & $\circ$ & $\circ$ \\
\hline \multicolumn{11}{|l|}{ Administration } \\
\hline $\begin{array}{l}\text { Accepts applications for persons with disabili- } \\
\text { ties by mail }\end{array}$ & $\circ$ & - & - & $\circ$ & $\circ$ & - & $\circ$ & - & - & $\circ$ \\
\hline Accepts older adult applications by mail & $\circ$ & $\circ$ & $\bullet$ & $\circ$ & $\bullet$ & $\bullet$ & $\circ$ & $\bullet$ & $\circ$ & - \\
\hline $\begin{array}{l}\text { Maintains multiple transit agency customer } \\
\text { service centers }\end{array}$ & - & o & o & 0 & $\circ$ & - & o & $\circ$ & - & $\circ$ \\
\hline Maintains mobile registration program & $\bullet$ & $\circ$ & $\bullet$ & $\circ$ & $\circ$ & $\circ$ & $\circ$ & $\bullet$ & $\circ$ & $\circ$ \\
\hline $\begin{array}{l}\text { Maintains external service centers through } \\
\text { partnerships }\end{array}$ & 0 & $\bullet$ & - & - & 0 & $\circ$ & - & $\circ$ & $\bullet$ & 0 \\
\hline Transit agency prints/distributes reduced fare cards & $\bullet$ & $\bullet$ & $\circ$ & $\bullet$ & $\bullet$ & $\circ$ & $\bullet$ & $\bullet$ & $\bullet$ & $\bullet$ \\
\hline $\begin{array}{l}\text { External vendor prints/distributes } \\
\text { reduced fare cards }\end{array}$ & $\circ$ & $\circ$ & - & $\circ$ & $\circ$ & - & 0 & $\circ$ & $\circ$ & $\circ$ \\
\hline
\end{tabular}

- = yes; $\circ=$ no; - = not applicable 
Free transit is frequently offered to older adults as a political expediency. For example, the programs in Chicago and Miami both originated as part of successful campaigns to increase local sales taxes hypothecated for transit. Given the size of the older adult population, this benefit can be quite costly, and transit systems have developed different solutions for restricting the class of eligible users. All cities have a residency requirement. Chicago introduced a means test after the transit agency found its "all seniors ride free" policy cost $\$ 30$ million a year in lost fares (Hilkevitch 2011). Houston set the threshold for free travel at age 70 . Chicago also provides free fixed-route transit to people with disabilities who pass a means test. This program originated as part of the legislation that introduced the now curtailed "all seniors ride free" policy. No other surveyed system offers free rides to non-ADA paratransit eligible riders with disabilities.

While offering free fixed-route travel to ADA paratransit users results in a net gain for transit agencies, offering the same benefit to non-ADA paratransit users, whether older adults or people with disabilities, results in a net loss. Ideally, the transit agency would be fully reimbursed for these free trips; however, the only program to explicitly do so was found in Philadelphia. There, the state reimburses the transit operator on a full fare basis for each free trip made by an older adult with proceeds from the state lottery. These reimbursement rates are higher than the actual per-trip revenues collected by paying customers, which incentivizes the transit agency to promote the free ride program (Fish 1996). By contrast, in Chicago, transit agencies receive only partial reimbursement from the state for lost fare revenues.

\section{Technology}

There are two types of reduced fare permit technologies, as shown in Table 2. The first type, which is less prevalent today, is a simple identity card that functions as a flash pass the user shows the driver or ticket agent to claim the reduced fare benefit. These cards are entirely distinct from existing transit fare media. Dallas, Philadelphia, and Washington issue such cards for riders with disabilities and Dallas and Philadelphia issue them for older adults. Many regions allow older adults to use a government identification card to claim the reduced fare benefit. Washington relies exclusively on government identification cards and does not issue its own reduced fare permits for older adults, a policy that reduces administrative demands.

The second type of permit technology, which is currently predominant, combines an identity card with the transit system's fare media. This merger is typically accomplished by personalizing the back of a standard fare card. These cards function as 
fare media coded to automatically offer the appropriate reduced fare benefit. This permit technology typically still functions as the simpler identification-only card on commuter rail.

The general technology trend has been to move towards the combined cards, which reduces the total number of products needed to be carried by customers. Philadelphia, which is currently transitioning to a contactless open fare payment system, is planning to issue a combined identity and fare smartcard for people with disabilities. Dallas may also be inching in this direction, as the region has recently begun selling an annual pass for older adults that merges identity and fare elements.

\section{Administration}

Administration refers to the central processing tasks transit agencies undertake to enroll and authorize participants in a reduced fare program. These tasks are registration, renewal, and replacement. Registration is the process through which potential users apply to participate in the program and receive their initial reduced fare card. Renewal is the process at the end of the program term through which existing users' accounts are updated and new permits are distributed. Replacement is the procedure through which an existing user receives a new permit for any reason other than the expiration of the program term.

\section{Registration}

Registration is the most labor intensive of the three "Rs" of administration, as it involves processing applications to determine eligibility and printing and distributing the reduced fare cards.

The applications themselves are quite consistent among the surveyed agencies. People with disabilities must produce documentation, typically a note from a medical professional, which attests to the nature and mobility impact of the disability. Older adults must produce government identification showing they have met an age threshold. That threshold is age 65 in all surveyed regions except for Los Angeles, which exceeds the federal requirement and qualifies older adults at age 62.

Agencies vary, however, on how they interact with applicants. Transit agencies must balance the desire to run an efficient operation with the competing need to make the program accessible to applicants. This tension is present in the federal regulations, which state that the Federal Transit Administration (FTA) "strongly encourages operators to develop procedures that maximize the availability of offpeak half-fares to eligible individuals. Requiring individuals to travel to a single office 
that may be inconveniently located is not consistent with this policy, although it is not strictly prohibited. FTA reserves the right to review such local requirements on a case-by-case basis" (U.S. Department of Transportation 1976).

One option is to offer multiple agency service centers within a region, which reduces the average distance customers will need to travel. Table 2 demonstrates that although most systems maintain a single, centrally-located, agency-staffed customer service center, Atlanta maintains two and Los Angeles maintains four. Philadelphia maintains one center for accepting applications from persons with disabilities, but has four centers for accepting older adult applications.

Another approach is for agencies to come to the applicants. Several systems offer mobile registration services through which an agency employee will bring the necessary registration forms and equipment (computer, digital camera, card printer, etc.) to different locations around the region. Atlanta and New York offer this service regularly, whereas Chicago does so occasionally, and Boston did so in the past. Offering mobile services requires coordination with the hosting location as well as additional capital and setup costs. New York has streamlined this process by retrofitting two 40 -foot buses and three 20-foot vans as mobile sales and customer service centers (Parker, Timson, and Henning 2000).

A third approach is partnering with external agencies. Miami allows applications from persons with disabilities and older adults to be completed at three customer service centers of the county government, and Philadelphia allows older adult reduced fare card applications to be completed at more than 20 state representatives' district offices. In both cases, the applications are then forwarded to the transit agency for processing. Boston, Chicago, and Dallas have extended these relationships more broadly and incorporate non-government agencies. Boston maintains more than 50 external centers for older adult applications. Chicago maintains 52 external centers for reduced fare card applications for persons with disabilities and 185 centers for older adult reduced fare card applications. Dallas maintains 45 external centers for reduced fare cards for persons with disabilities. These external locations include social service organizations, town halls, senior centers, bank branches, etc., that volunteer their efforts to assist in the preparation of reduced fare card applications. In Boston and Chicago, these centers prepare and mail applications to the transit agency. In Dallas, these centers not only prepare applications but certify disability status on the spot.

The Dallas example warrants special mention. Dallas Area Rapid Transit (DART) actively trains (and audits) its partner agencies. These DART-Approved Certifying 
Agencies (DACAs) enter approved applicant information directly into the DART database via the Internet. The local DACA retains hard copies of the application material and prints out a receipt for the approved applicant. That applicant then takes this receipt to DART's main office to pick up his or her reduced fare card. DART's high level of training and supervision allows the transit agency to outsource disability certification to volunteers. Furthermore, those trusted partners are able to avoid extra paper handling and the attendant delay by electronically (and instantly) entering applicant information into DART's database. The requirement to come downtown to pick up the actual card may be burdensome, as only 73 percent of certified applicants actually claimed their card in 2011. This disjunction suggests that the current policies are either inadequately serving patrons or, alternatively, sorting out the people most likely to use the reduced fare card.

A final option is to accept applications by mail. Table 2 shows that half the surveyed agencies accept applications by mail, while the other half requires in-person applications. Offering the mail option makes it easier for the customer, who does not have to travel to a registration site, but reduces the agency's ability to ensure that the applications are filled out correctly and truthfully. In-person applications can be corrected on the spot and allow the agency to better verify applicant identity. Furthermore, in-person applications allow for digital photography, which makes for more consistent, higher-quality cards than scanning externally-submitted pictures. Agencies with larger numbers of reduced fare users reported that offering the mail option was necessary, as there would not be sufficient staff to handle the demand of in-person only applications.

Once an agency has approved an application, a permit must be produced. Agencies vary on whether they print these cards themselves or outsource the task. Outsourcing always adds an extra process, which extends the time until the card is in the hand of the user. Los Angeles and Chicago have chosen to outsource permit printing and deal with the long turnaround times by giving in-person applicants an interim reduced fare card good for 60-90 days. In-house printing may leave an agency vulnerable to staffing reductions. New York, for example, reduced its staff and has had trouble getting cards to customers (Donohue 2012). Agencies also vary on whether they charge for printing the permits. Dallas charges a $\$ 2$ fee for both older adults and persons with disabilities to cover the cost of photo. Los Angeles charges a $\$ 2$ processing fee for reduced fare cards for persons with disabilities, but not for older adults. No other system charges a printing fee, which might be seen as an undue impediment to receiving a legally-guaranteed benefit. 
The third and final step to registration is distributing the permits to customers. These can be either mailed or picked up in person. Generally, cards are returned in the same way that the initial application was delivered. If the application was mailed to the agency (either by the applicant or a remote center), the card is mailed to the applicant. The distribution time ranges from two to eight weeks. (The number of weeks required to return the card to the patrons reported in surveys tended to be longer than those advertised on agency websites, sometimes by a factor of two.) If the application was delivered in person, the card is often produced on the spot. There are some exceptions. As noted above, Chicago and Los Angeles do not print their own cards, so their walk-in applicants receive their cards in the mail in about a month; Philadelphia returns all reduced fare cards exclusively by mail even though they do not accept older adult applications by mail; and Boston requires that all riders with disabilities pick up their permits in person, even if the applications were delivered by mail.

Some systems, like Atlanta and Dallas, distribute cards only in person. This approach puts a travel burden on the user, but has several advantages for the transit agency. The agency can be certain that the permit has been received and that it has been received by the actual applicant. The applicant can sign a statement acknowledging receipt, which may head off future legal problems. In-person distribution eliminates the need for issuing temporary cards as well as any mailing costs. In Miami, people who apply at remote government centers need to return to those centers to pick up the reduced fare permit in-person. In-person distribution can strain agency staff and was reported to not be feasible in regions with high numbers of both residents and transit trips (see Table 1), as such systems, consequently, have high numbers of reduced fare applicants.

\section{Renewal}

Every agency surveyed except Philadelphia requires that reduced fare permits for older adults and persons with disabilities be renewed on a regular basis. This requirement keeps the registration lists current by eliminating people no longer interested or eligible to remain in the program. It also forces a turnover in the card stock, which reduces fraud by capping the length of time that cards can be used illegally (i.e., by someone other than the named cardholder). This turnover may be necessary, as electronically-coded media, such as smartcard and magnetic stripe cards, are designed with limited useful life expectancies. Philadelphia does not currently use electronically-coded cards for its reduced fare media and, therefore, is able to offer lifetime terms of card validity. 
Term lengths are set to balance the costs of processing renewals with the costs of lost revenue from fraudulent use of the cards. Figure 1 demonstrates that there is substantial variation in permit term lengths. Part of that variation can be attributed to the condition that warrants the reduced fare. On average, temporary disabilities (i.e., those for which recovery is expected) have the shortest terms and older adults have the longest terms, with permanent disabilities in the middle. In practice, only Boston reflects this tripartite variation, as regions tend to coordinate the terms either for temporary and permanent disabilities or for permanent disabilities and older adults. Most agencies offer fixed terms for all conditions; however, fixed terms for temporary disabilities may result in time periods when a rider who no longer has a disability can legally enjoy a reduced fare. To address this problem, Chicago, Houston, Los Angeles, and New York offer riders with temporary disabilities a variable term based on the expected recovery time, up to a limit ranging from one to four years, as shown in Figure 1.

Renewing reduced fare permits requires agencies to alert their permit holders to the impending card expiration. The lowest cost approach is to simply print the expiration date on the reduced fare card itself, which is done by all the surveyed systems except Atlanta and Miami. Atlanta plans to embrace this practice soon. Miami alerts customers by flashing a digital message on the farebox or turnstile when the permit is used. Since Miami structures all of its disabled reduced fare cards to expire the same day (September 30), the agency can further alert those customers through advertisements. A more expensive approach taken by Atlanta, Chicago, Houston (only for older adults), and Los Angeles is to mail notices to permit holders. This approach has the advantage of reaching people who may not be active card users. There is variation in how much warning time agencies provide. Atlanta provides 30 days, Chicago provides 60 days, and Los Angeles provides 90 days.

Renewing reduced fare cards also requires agencies to verify that current permit holders should remain in the program. Agency policies trade off convenience for a high certainty of verification. At the two extremes, Dallas and Los Angeles require customers with permanent disabilities (as well as older adults in Dallas) to repeat the entire certification process at the end of every term (which in Dallas is one year), while Houston automatically sends out new cards. Miami represents a middle ground by requiring proof of ongoing permanent disability by fax, mail, or in person, but not full recertification. 


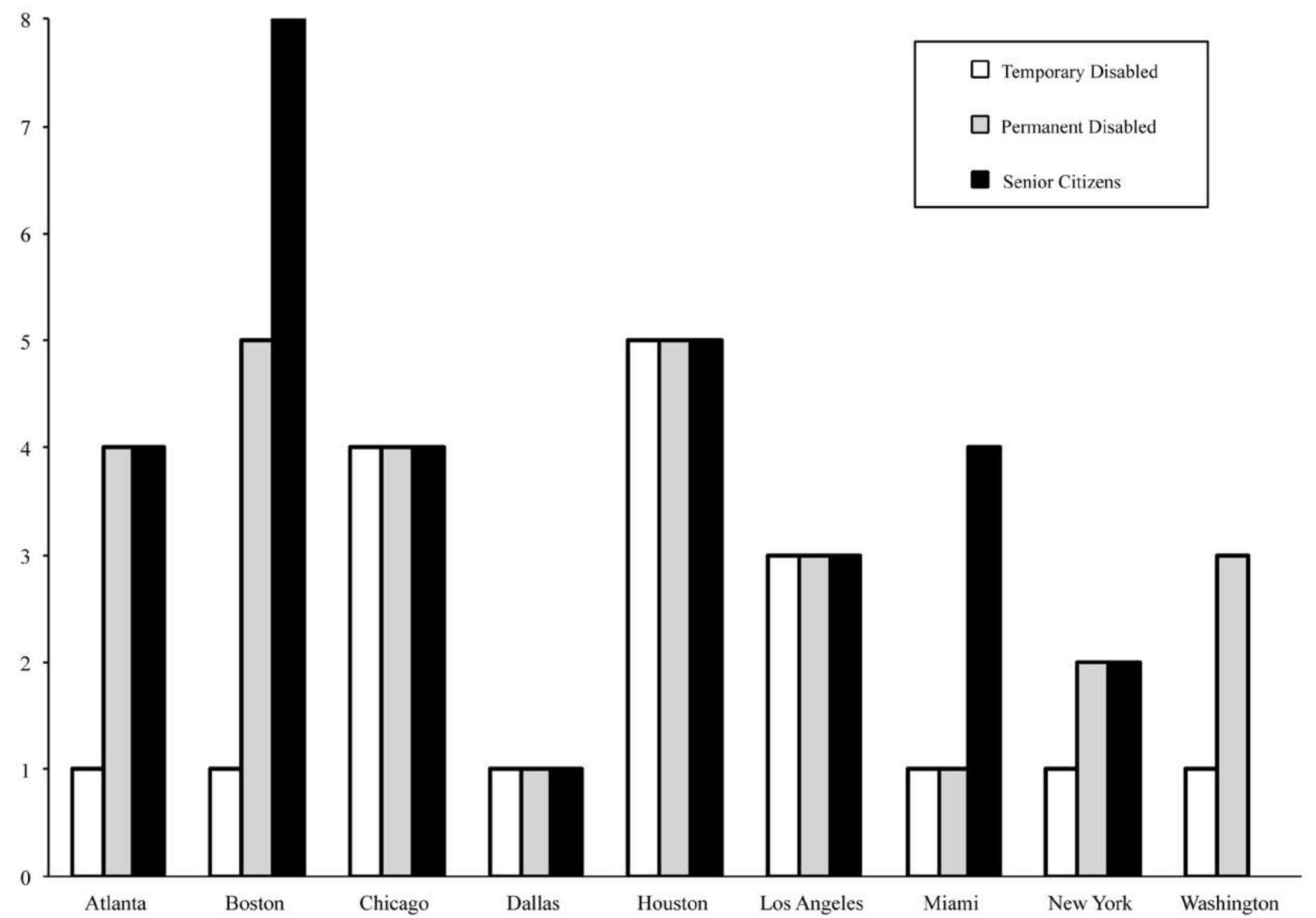

Notes: Washington does not register older adults. All terms are fixed except for temporary disabled terms in Chicago, Houston, Los Angeles, and New York, where they vary up to the limit shown in this figure. Philadelphia is not included in this chart since there are no fixed terms; instead, the card is issued either for the expected length of a temporary disability or for life.

Figure 1. Reduced fare card renewal terms (in years) 
A main concern for many systems is verifying that the cardholder is alive and wants to remain in the program. Atlanta and Washington (for riders with disabilities) require the customer to visit a customer service center in person to get a permit renewal. Chicago and Los Angeles (for older adults) send a form that the customer must fill out and return. Boston allows cardholders to call in their verification. New York automates verification by checking the Social Security Administration database to ensure that the cardholder is still alive before sending out a new permit.

\section{Replacement}

A portion of reduced fare cards will need to be replaced before they reach the end of their term, either because the card is missing or because the card is no longer usable. The former occurs when the card is lost, stolen, or never received through the mail. The latter occurs when the card has been confiscated due to improper use, damaged to the point of inoperability, captured in a fare box or ticket vending machine, or needs to be replaced due to a technology change.

The general replacement approach is to, ideally, deactivate missing cards or destroy unusable cards and then place any remaining value on a new card. Deactivation is possible for those cards that incorporate electronic fare media, whether magnetic stripe or smartcard. These cards can be remotely deactivated by adding their identification number to a "hotlist" of invalidated card numbers to be rejected by fare readers. This approach does not prevent reduced fare cards from functioning as flash passes, does not affect identification-only cards, and entails some data storage limitations. Destruction is the preferred solution but can be used only for cards whose whereabouts are known. Many transit agencies will seek to have unusable cards returned to them for shredding before issuing a replacement.

Since replacement entails processing expenses and may introduce the possibility of fraud, transit agencies prefer that patrons hold on to and take care of permits. A variety of disincentives are used to discourage the need for replacement from arising. The most common disincentive is to charge replacement fees.

Figure 2 shows that 8 of the 10 agencies surveyed charge such fees. Most of these charge only when the customer can reasonably be held culpable, i.e., he or she has misplaced the card or "loaned" it to someone from whom it was later confiscated; however, Los Angeles also charges if the customer has damaged a card-for example, by punching a hole in it to thread a lanyard-and Miami charges if a customer claims he or she never received the card, but the card was sent to the correct address and the card was used. The fee amounts vary rather significantly, 
from $\$ 1$ to $\$ 25$, and four of the systems charge escalating fees for subsequent replacements. Both the fee amounts and the incidence of escalation have gone down with the ability to remotely deactivate electronic fare media and, therefore, reduce the potential revenue losses from the fraudulent use of missing cards. For example, both Atlanta and Boston used to charge higher and escalating fees, but dropped the base level (in Atlanta to a token dollar and in Boston entirely) and the escalation framework with the transition to smartcards. (Boston's decision was also motivated by a concern that the fees fell disproportionately on riders whose disabilities, particularly cognitive, make it difficult to manage their cards.) By contrast, Philadelphia and Washington, which both use identity cards that cannot be remotely deactivated, charge the highest replacement fees and maintain escalation structures. Transit agencies typically have the right to waive these fees either at their discretion or as part of a structured program. An example of the latter is Houston, which allows a one-time fee waiver.

Several systems offer administrative disincentives to replacement. For example, Dallas requires riders to repeat the entire application procedures to receive a replacement card, regardless of the reason for replacement. Philadelphia will not issue a second replacement card for older adults until a year elapses from the time of the first replacement. In the case of confiscated cards, Atlanta delays replacement for 30 days and increases that delay by 30 days for each subsequent confiscation. New York has such patrons wait 60 days for a replacement card. Boston allows one "freebie" of fraudulent use and then can cut such owners from the reduced fare program altogether, a rarely-implemented policy provision of Massachusetts state law unlikely to pass a federal challenge. 


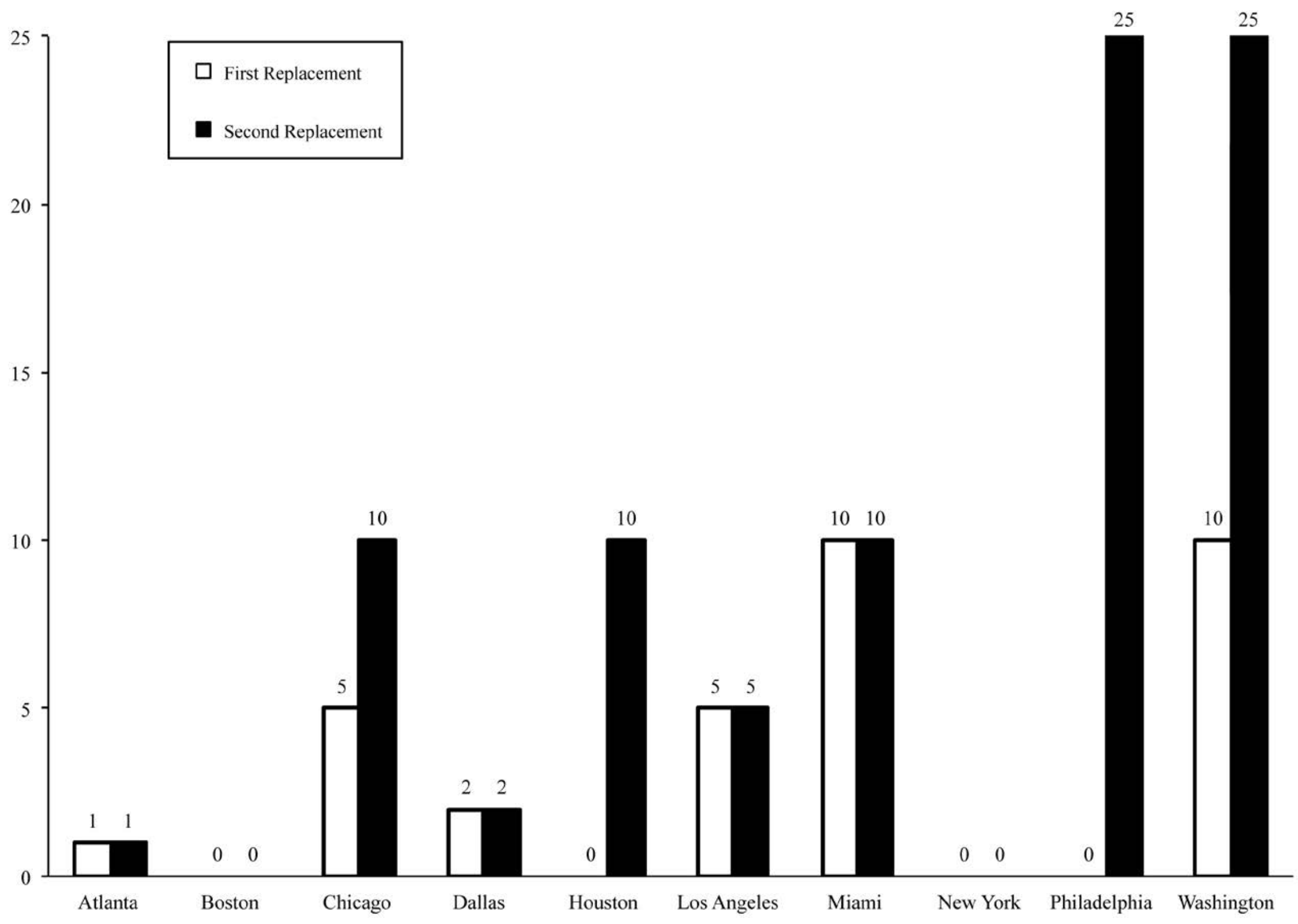

Figure 2. Reduced fare card replacement fees (\$) 


\section{Fraud Prevention}

Since reduced fare cards offer significant savings, they incentivize fraud. The main reported agency concern is non-eligible people using legitimate reduced fare permits obtained either as a loan/gift/bequest from the eligible user or through robbery. (A secondary concern, raised by one respondent as justification for requiring in-person applications, is that ineligible people may be fraudulently registering for legitimate permits. This concern does not appear to be widely shared as systems seem confident of their registration processes.) The administration procedures discussed above provide a general framework for making sure that permits initially go to the right people and that errant permits are deactivated. This section addresses how transit systems enforce use of the permits by the authorized cardholder.

Enforcement first requires that the reduced fare permit be sufficiently personalized to identify that the card user is the legitimate cardholder. At the same time, agencies are concerned about possible downsides for the user of too much data collection. For example, Chicago does not currently put the user's name on the card to protect the cardholder's identity in the case of theft. (Chicago has decided to include names as part of a new permit policy starting in late 2013.) Houston does not put the user's picture on the older adult card to not burden those users with the inconvenience of coming to a service center to be photographed. Many systems use card design to augment the personalization. The most sophisticated approach is used in New York, where reduced fare cards come in four background colors that distinguish between men and women as well as between older adult riders and riders with disabilities. These markings facilitate spot checking by enforcement agents.

Such enforcement is critical to preventing fraud, but varies significantly, particularly among the rail portions of the surveyed systems. The most secure rail systems, such as Philadelphia, require everyone using a reduced fare card to be manually checked upon entry. This approach slows boardings but is thought to result in very little abuse of the cards. Less-secure rail systems, such as Dallas, Houston, and Los Angeles, have (at least for now) barrier-free entry but maintain teams of roving fare inspectors to check for fraud and similarly report limited abuse of the reduced fare cards. The remaining rail systems in the sample all allow anonymous entry, which is the least secure approach. These systems consequently report greater concerns about fraud. Boston, Chicago, Miami, and New York note that their fare gates have indicator lights or specified tone sequences that mark when someone pays a concessionary fare. These agencies send roaming inspectors to challenge suspi- 
cious users for proof of reduced fare eligibility. Atlanta and Washington have no structured monitoring program at their rail stations.

There is slightly more enforcement consistency on buses as, at least in theory, the driver is supposed to keep tabs on reduced fare use. Dallas and Philadelphia, which require the driver to check for a reduced fare permit before offering discounts, are the most secure. Many systems have fareboxes that emit different tones or lights to identify when a reduced fare payment is being made; however, it is up to the discretion of a bus driver to challenge potentially fraudulent use. New York is unique in sending fare inspectors onto buses to improve reduced fare permit enforcement.

The shift to electronic fare media does afford some new possibilities for data mining to combat fraud. New York is the only system to report examining usage patterns to identify fraudulent behavior and target enforcement locations. Chicago and New York hotlist the cards of people that have died, based on Social Security records. In Chicago, this practice began after an audit exposed one older adult reduced fare card being used more than a thousand times after its owner had passed away (Regional Transportation Authority Research, Analysis \& Policy Development Department 2010). Hotlist capacity is often limited and, at a certain point, new additions bump off older numbers, which raises the specter of deactivated cards once again becoming useable. Chicago has addressed this storage limitation by splitting the hotlist in two. An active list maintains the current crop of bad card numbers for several weeks before transferring them to an offline passive list. Card use is monitored, and if a card number from the passive list appears in the usage records, then that number returns to the active hotlist.

Accessing the Social Security database requires transit agencies to collect cardholder Social Security numbers. Some agencies, such as Miami, find such unique identifiers critical for tracking program registrants in a region where many people have the same names. Other agencies report concerns about handling such sensitive information. Boston, for example, has ceased collecting Social Security numbers, having decided that the costs of possible data exposure outweighed the fraud prevention benefits.

\section{Conclusions}

The variation in reduced fare card policies across the United States offers an excellent opportunity for transit agencies to learn from each other's experience and to mix and match approaches that best meet their specific needs. This paper provides a framework for understanding that variation and then illustrates it with examples 
from the largest metropolitan areas in the United States to illuminate policy tradeoffs. This work is aimed at helping agencies review and refine their reduced fare policies.

The need for such policy reconsideration is likely to grow. The aging of the population will continue to strain reduced fare program administration, as can be seen in New York; the transition to contactless fare payment technologies will require many agencies to reissue reduced fare permits en masse and foster a rewriting of the associated policies, as is currently underway in Chicago; and, finally, the slow shift from paper-based to electronic information management will offer new opportunities for streamlining program administration as demonstrated in Dallas. Even in the absence of external impetus for change, the information presented in this paper will assist in the always useful practice of policy revision.

\section{Acknowledgments}

The author would like to thank Mark Minor, John G. Allen, Peter Fahrenwald, Jaime Garmendia, Diane Palmer, Vickie Bradley, Anne LeFevre, Annette Long, and Rosemary Gerty for commenting on drafts, as well as all the survey respondents who shared their time and insights.

\section{References}

Allen, Karin. 2013. Determination of regional peer agencies. Chicago: Regional Transportation Authority.

Andrews, G., G. Parkhurst, Y. O. Susilo, and J. Shaw. 2012. The grey escape: Investigating older people's use of the free bus pass. Transportation Planning and Technology 35(1): 3-15.

Baker, S., and P. White. 2010. Impacts of free concessionary travel: Case study of an English rural region. Transport Policy 17(1): 20-26.

Donohue, Peter. 2012. Fare level of anxiety: Getting senior Metrocards is a chore. New York Daily News, May 6.

Fish, Larry. 1996. SEPTA makes a pitch to lure more older riders. Philadelphia Inquirer, August 30, City and Region. 
Gallucci, Grace, and John G. Allen. 2011. Regional transit performance measures at Chicago's Regional Transportation Authority. Washington, DC: Transportation Research Board, National Academy of Sciences.

Goldstein, Sid. 2013. New York offers free fare card for ADA riders on fixed route. Transit Access Report, February 11.

Hilkevitch, Jon. 2011. Confusion, frustration greet new reduced-fare transit cards. Chicago Tribune, August 25, Final edition, News.

Hoel, L. A., and E. S. Roszner. 1972. Impact of reduced transit fares for the elderly. Traffic Quarterly 26(3): 341-358.

Ketron, Inc., and Urban Mass Transportation Authority. 1981. A review of half fare programs for the elderly and handicapped in the tri-state region. NY-09-0046 Final Report; TS A-230. Washington, DC: Urban Mass Transit Administration.

Ling, D., and K. Howcroft. 2007. The cost \& consequences of free local public transport for older \& disabled people in Greater Manchester. 11th International Conference on Mobility and Transport for Elderly and Disabled Persons: 18-22.

Metro Staff. 2012. DC Metro's revamped paratransit program saves $\$ 25$ million. Metro Magazine, October.

Metz, D. 2003. Transport policy for an ageing population. Transport Reviews 23(4): 375-386.

Morlok, E. K., W. M. Kulash, and H. L. Vandersypen. 1971. The effect of reduced fare plans for the elderly on transit system routes. TRD-97. Washington, DC: Urban Mass Transit Administration.

Newman, Philip. 2012. Free access-a-ride cards could save MTA \$90. Times Ledger, July 10 , News.

Parker, R., K. Timson, and B. Henning. 2000. Marketing automated farecards to senior citizens and disabled individuals: MTA NYC Transit's Metrocard buses and vans at work. Bus and Paratransit Conference Proceedings, American Public Transportation Association: 24-37.

Regional Transportation Authority Research, Analysis \& Policy Development Department. 2010. Seniors ride free fraud audit-Deceased card holders. Final report. Chicago: Regional Transportation Authority. 
Rock, S. M. 1979. The redistributive effects of reduced transit fares for the elderly. Transportation Research Part A: General 13(5): 361-365.

Roszner, E. S., and L. A. Hoel. 1971. Impact on transit ridership and revenue of reduced fares for the elderly. URT-5. Washington, DC: Urban Mass Transit Administration.

RTA Department of Finance and Performance Management. 2013. 2011 regional peer report card. Chicago: Regional Transportation Authority.

Rye, T., and W. Mykura. 2009. Concessionary bus fares for older people in Scotland-Are they achieving their objectives? Journal of Transport Geography 17(6): 451-456.

Rye, T., D. Seaman, D. McGuigan, and D. Siddle. 2002. Concessionary fares in Britain: What we need to know. World Transportation Policy \& Practice 8(2): 36-41.

Schmöcker, J. D., M. A. Quddus, R. B. Noland, and M. G. H. Bell. 2008. Mode choice of older and disabled people: A case study of shopping trips in London. Journal of Transport Geography 16(4): 257-267.

Shmelzer, J. L., and E. J. Cantilli. 1970. Elderly ridership and reduced transit fares: The Chicago experience. Transportation and Aging: Selected Issues. Washington, DC: US Government Printing Office.

Truelove, P. 1984. Transport usage by the elderly holding free travel passes. Proceedings of the International Conference on Mobility and Transport of Elderly and Handicapped Persons, Orlando: 376-378.

U.S. Department of Transportation. 1976. Transportation for elderly and handicapped persons. 49 CFR.

\section{About the Author}

GreGory L. NeWmaRK (gnewmark@cnt.org) is a senior research analyst at the Center for Neighborhood Technology (CNT), a research fellow at the Chaddick Institute for Metropolitan Development at DePaul University, and a lecturer at the Harris School of Public Policy Studies at the University of Chicago. He conducted this research while working as a principal analyst in the Planning Department of the Regional Transportation Authority in Chicago. 